\title{
Suplementação de novilhas leiteiras em pastagem de capim marandu na época das águas
}

\section{Supplementation of dairy heifers in tropical marandu grass during the rainy season}

\author{
Ricardo Dias Signoretti ${ }^{1}$, Bruna Pessim² ${ }^{2}$, Maira Mattar ${ }^{2}$, Brigida Sperchi de Oliveira Machado \\ ${ }^{1}$ Polo Regional de Desenvolvimento Tecnológico dos Agronegócios da Alta Mogiana (PRDTA - Alta \\ Mogiana), Agência Paulista de Tecnologia dos Agronegócios (APTA), Secretaria de Agricultura e \\ Abastecimento do Estado de São Paulo (SAA) - Colina (SP), Brasil. \\ ${ }^{2}$ Centro Universitário da Fundação Educacional de Barretos (UNIFEB) - Barretos (SP), Brasil.
}

\begin{abstract}
Resumo
Objetivou-se avaliar os efeitos de diferentes níveis de suplementação, na época das águas do ano, em relação ao desenvolvimento corporal de novilhas leiteiras mestiças Gir x Holandês, com idade média de 12,9 $\pm 1,58$ meses e com peso corporal (PC) médio inicial de 243,48 $\pm 26,00 \mathrm{~kg}$, distribuídas em delineamento de blocos ao acaso, com sete repetições por tratamento, em quatro módulos com seis piquetes cada, em pastagem de Brachiaria brizantha cv. Marandu, manejado em sistema intermitente. Os tratamentos consistiram no fornecimento de suplemento na quantidade de $0,3,0,6$ e $0,9 \%$ do PC e controle (sal mineral). Não foram observadas diferenças $(\mathrm{P}>0,05)$ em relação à altura do dossel na entrada, na oferta de forragem, expressa em $\mathrm{kg}$ de massa seca, $\mathrm{kg}$ de massa verde seca, $\mathrm{kg}$ de folha verde por $100 \mathrm{~kg}$ de PC, e na taxa de lotação (UA ha-1) entre os ciclos de pastejo. Foi observado aumento linear $(\mathrm{P}<0,001)$ com as doses crescentes do suplemento no ganho de peso diário (kg dia-1), no perímetro torácico final $(\mathrm{cm})$, no comprimento da garupa final $(\mathrm{cm})$ e na condição corporal final. Foram realizadas análises de variância e de regressão entre os dados de PC e as doses suplementadas por meio do pacote estatístico SAS. Ao final de cada ciclo de pastejo, os animais foram pesados e mensurados quanto à altura na cernelha, perímetro torácico, comprimento da garupa e condição corporal. Conclui-se que as novilhas apresentaram melhor desempenho quando suplementadas com energia e proteína em comparação a animais suplementados somente com sal mineral.
\end{abstract}

Palavras-chave: desenvolvimento corporal; ganho de peso; pastejo; novilhas em crescimento.

\begin{abstract}
The aim of this study was to evaluate the effects of different levels of supplementation, in the rainy season of the year, on body development of dairy crossbred Holstein-Gir, with a mean age of $12.9 \pm 1.58$ years and a mean early body weight of $243.48 \pm 26.00 \mathrm{~kg}$, distributed in a randomized block design with seven replicates per treatment, in four modules each with six paddocks. The study used Brachiaria brizantha cv. Marandu grazing, managed in an intermittent system. Treatments consisted in providing supplement (corn, soybean meal, urea, ammonium sulfate, salt and mineral salt), $20 \%$ crude protein as-fed basis, in the amount of $0.3,0.6$ and $0.9 \%$ of body weight (BW) and control (mineral salt). Analysis of variance and regression between body weight data and supplemented doses and estimated using the SAS statistical
\end{abstract}

Autor para correspondência: Maira Mattar - Centro Universitário da Fundação Educacional de Barretos (UNIFEB) - Avenida Prof. Roberto Frade Monte, 389 - Bairro Aeroporto - CEP: 14783-226 - Barretos (SP), Brasil-E-mail: mairamattar@hotmail.com

Recebido em: 11 de abril de 2017

Aceito para publicação em: 08 de novembro de 2017 
procedure. At the end of each grazing cycle (36 days) the animals were weighed and measured for height at withers, heart girth, rump length and body condition score. The conclusion is that heifers maintained on the same pasture conditions during the rainy season showed better performance when supplemented with energy and protein compared to animals supplemented only with mineral salt.

Keywords: body growth; weight gain; grazing; growing heifers.

\section{Introdução}

A criação de novilhas de reposição tem por objetivo conseguir crescimento adequado, de forma que esses animais tenham precocidade na idade o mais cedo possível ao primeiro parto, a baixo custo, e que possam substituir prontamente vacas descartadas do rebanho em lactação, com retorno do investimento do produtor em alimentação, da mão de obra, entre outras, pois a recria representa de 20 a $25 \%$ do custo na atividade leiteira (PERES et al., 2008).

$\mathrm{Na}$ época das águas, as taxas de crescimento e desenvolvimento das plantas são favorecidas pelo aumento da luminosidade, temperatura e precipitação. Nessa época, a composição química da forragem disponível não é constante, uma vez que o crescimento das plantas é intenso e variável. Assim, devem ser aplicadas técnicas de manejo no pasto com intuito de permitir que os animais possam ingerir forragem de melhor qualidade $\mathrm{e}$ apresentem boas taxas de crescimento. Além disso, podem ocorrer algumas interações do animal com o pasto, as quais tendem a causar mudanças significativas na qualidade da forragem selecionada (DETMANN et al., 2014).

Contudo, um dos fatores preponderantes em relação à produção de animais em sistema de suplementação a pasto consiste na definição dos objetivos principais dessa suplementação dentro do sistema de produção existente (PAULINO; DETMANN; VALADARES FILHO, 2008). Consequentemente, devem-se estabelecer estratégias de fornecimento de nutrientes que viabilizem, da melhor forma possível, os padrões de crescimento estabelecidos pelo sistema de produção (VILLELA et al., 2010), além de auxiliar no manejo da pastagem, entre outros benefícios (REIS; BARBERO; KOSCHECK, 2014).

Segundo Valente (2015), Oliveira (2014) e Casagrande et al. (2011), existe um ganho latente adicional de aproximadamente $300 \mathrm{~g} / \mathrm{animal} / \mathrm{dia}$, que pode ser atingido com o correto manejo das pastagens e o uso da suplementação.
Dessa forma, a utilização de suplemento na época das águas é uma opção para o suprimento de nutrientes limitantes, o que contribui para aumentar a eficiência de utilização das pastagens e do consumo de nutrientes digestíveis (PORTO et al., 2009), diminuindo, assim, os ciclos dos bovinos em regime de pastejo e melhorando o retorno econômico.

Objetivou-se com este trabalho avaliar diferentes níveis de suplementação na época das águas sobre o desenvolvimento corporal de novilhas mestiças leiteiras, buscando-se antecipar a entrada dos animais em sua fase produtiva.

\section{Material e Métodos}

$\mathrm{O}$ experimento foi conduzido na unidade de pesquisa do Polo Regional de Desenvolvimento Tecnológico dos Agronegócios da Alta Mogiana (PRDTA-Alta Mogiana), em Colina/SP, órgão da Agência Paulista de Tecnologia dos Agronegócios, da Secretaria de Agricultura e Abastecimento do Estado de São Paulo.

O PRDTA-Alta Mogiana está localizado no município de Colina, Estado de São Paulo (latitude de $20^{\circ} 43^{\prime} 05^{\prime}$ ' S; longitude $48^{\circ} 32^{\prime} 38^{\prime \prime} \mathrm{W}$ ). A precipitação pluviométrica e a temperatura máxima e mínima, em média, durante o período experimental de 158 dias (05/01/2010 a 12/06/2010) foram de $758,9 \mathrm{~mm}, 32,8^{\circ} \mathrm{C}$ e $15,9^{\circ} \mathrm{C}$, respectivamente.

Foram utilizadas 28 novilhas mestiças leiteiras Gir x Holandês com peso corporal (PC) médio inicial de $243,48 \pm 26,00 \mathrm{~kg}$ e com idade média de $12,9 \pm 1,58$ meses, distribuídas em delineamento de blocos ao acaso, com sete repetições por tratamento, em quatro módulos com seis piquetes cada, em pastagem de Brachiaria brizantha cv. Marandu. O critério para confecção dos blocos foi o peso inicial de entrada. No início do período experimental, os animais foram desverminados, vacinados e identificados individualmente; em seguida, passaram por um processo de adaptação por 14 dias, sendo mantidos por 144 dias na pastagem. 
Durante todo o período experimental, foram realizados os controles rotineiros de ectoparasitos e as desverminações necessárias.

No início e final do experimento e a cada período de 36 dias, após jejum completo de 16 horas, os animais foram pesados individualmente em balança e medidos quanto ao perímetro torácico (perímetro imediatamente caudal à escápula, passando pelo esterno e pelos processos espinhais das vértebras torácicas), altura de cernelha (medida pela distância em centímetros do solo à cernelha, estando o animal com a cabeça levantada, por meio de régua métrica metálica), o comprimento da garupa (medida com bastão hipométrico) e o escore da condição corporal, conforme metodologia de Wildman et al. (1982).

O PC médio do lote foi usado para os cálculos de ajuste da carga animal (mínimo de $12 \mathrm{~kg}$ de MS/100 kg de PC) e da quantidade de suplemento oferecido.

A técnica utilizada para manter o consumo da forragem disponível sem submetê-la a sub ou superpastejo foi o método "put and take", ou seja, carga fixa com taxa de lotação variável. Os animais utilizados para ajuste da oferta de forragem foram mantidos em área anexa próxima à área experimental, onde tinham à disposição a mesma gramínea e recebiam sal mineral, e, quando foram utilizados, passavam por todos os piquetes experimentais.

A área experimental, de 7,28 ha, foi formada com a forrageira Brachiaria brizantha cv. Marandu, subdividida em quatro módulos de 1,82 ha. Cada módulo constituído por seis piquetes manejados sob o método de lotação intermitente, com seis dias de ocupação e 30 dias de descanso em cada piquete, perfazendo ciclos de pastejo de 36 dias. A cada 18 dias, os animais foram rotacionados entre os módulos de piquetes, visando à eliminação de possíveis interferências sobre os resultados por causa das diferenças entre os módulos. Vale salientar que, no período experimental, a pastagem não foi fertilizada.

Foram avaliados os seguintes tratamentos experimentais: controle (somente sal mineral) e suplementação com concentrado na quantidade de $0,3,0,6$ e $0,9 \%$ do PC. A suplementação foi formulada para ganho de peso estimado de $1,0 \mathrm{~kg} / \mathrm{animal} / \mathrm{dia}$ (NATIONAL RESEARCH COUNCIL, 2001), conforme apresentado na Tabela 1. Os suplementos foram fornecidos em cochos coletivos na pastagem,
Tabela 1. Composição químico-bromatológica do capim Marandu e do suplemento utilizado em \% na MS.

\begin{tabular}{lcc}
\hline \multicolumn{1}{c}{ Itens } & Forragem & Suplemento \\
\hline Matéria seca & 23,7 & 89,9 \\
Proteína bruta & 10,3 & 20,2 \\
Fibra em detergente & 67,4 & 8,6 \\
neutro & & \\
Fibra em detergente & 32,7 & 4,7 \\
ácido & & \\
Celulose & 28,6 & - \\
Hemicelulose & 33,8 & 5,4 \\
Lignina & 3,9 & - \\
\hline
\end{tabular}

uma vez ao dia (10 horas), com objetivo de não interferir no pastejo durante o período da manhã (pico de pastejo). O suplemento utilizado possuía a seguinte composição: $70 \%$ de milho grão, $25 \%$ de farelo de soja, $0,9 \%$ de ureia, $0,1 \%$ de sulfato de amônia, $0,5 \%$ de sal comum e 3,5\% de sal mineral. Foi fornecido sal mineral durante todo o período experimental com os seguintes níveis de garantia por kg do produto: $138 \mathrm{~g}$ de $\mathrm{Ca}, 88 \mathrm{~g}$ de $\mathrm{P}$, $11,7 \mathrm{~g}$ de $\mathrm{Na}, 18,3 \mathrm{~g}$ de $\mathrm{Cl}, 20 \mathrm{~g}$ de $\mathrm{S}, 1.200 \mathrm{mg}$ de $\mathrm{Cu}, 3.400 \mathrm{mg}$ de $\mathrm{Zn}, 33 \mathrm{mg}$ de Se, $30 \mathrm{mg}$ de $\mathrm{Cr}, 80 \mathrm{mg}$ de Co e $70 \mathrm{mg}$ de I.

Mensalmente foi realizada a metodologia de dupla amostragem (SOLLENBERGER; CHERNEY, 1995). As equações para estimativa da massa de forragem foram determinadas para cada piquete correlacionando os valores da altura do dossel (prato ascendente) e massa de forragem (MORETTI et al., 2013). Para determinação dos componentes do dossel forrageiro, foi realizada a separação dos componentes, folha verde, colmo verde, folha seca e colmo seco em amostras obtidas na altura média.

Foram colhidas amostras pelo método de pastejo simulado (JOHNSON, 1978) para avaliar o valor nutritivo da forragem. As amostras obtidas foram secas em estufa, moídas em moinho de facas com peneira com malha de 1,0 $\mathrm{mm}$ para serem analisadas. Foram determinados os teores de matéria seca (MS), proteína bruta (PB) (ASSOCIATION OF ANALYTICAL CHEMISTS, 1975), fibra em detergente neutro (FDN) e fibra em detergente ácido (FDA) (ROBERTSON; VAN SOEST, 1981). A celulose foi solubilizada utilizando ácido sulfúrico a $72 \%$, sendo o resíduo a quantidade de lignina na amostra.

Os parâmetros relacionados ao desempenho animal foram avaliados por meio de delineamento 
de bloco casualizado, sendo considerado o módulo de pastejo (um módulo/tratamento), o tratamento (níveis de suplementação: 0, 0,3, 0,6 e 0,9\%) e o animal como repetição (sete animais/tratamento). Já no caso das avaliações de forragem, a unidade experimental foi o piquete (seis piquetes/módulo). O modelo proposto incluiu efeito de níveis de suplementação, ciclo de pastejo e interação tratamento-ciclo de pastejo conforme Equação 1 a seguir:

Yijk $=\mu+\mathrm{Ti}+\mathrm{Bj}+\mathrm{CPk}+(\mathrm{T} \times \mathrm{CP}) \mathrm{ik}+$ eijk

em que: Yijk é a variável analisada; $\mu$, a média geral; Ti, o efeito do tratamento $" i$;", sendo $i=1-0 \%$, $2-0,3 \%, 3-0,6 \%$ e $4-0,9 \%$ de suplemento por $100 \mathrm{~kg}$ de $\mathrm{PC} ; \mathrm{Bj}$, o efeito do bloco $\mathrm{mj}$, sendo $\mathrm{j}=1,2,3$ e 4; $\mathrm{CPk}$, o efeito do ciclo de pastejo "k", sendo k=1, 2, 3 e 4; (T x CP)ik, a interação entre o tratamento 1 "'e o ciclo de pastejo "k"; eijk, o erro aleatório residual.

As variáveis relativas ao desenvolvimento corporal foram submetidas a análises de variância e de regressão, considerando os efeitos de blocos e de níveis de suplementação e as características quantitativas e qualitativas do pasto os efeitos dos ciclos de pastejo ( 1 a 4 ), as quais foram analisadas como medidas repetidas no tempo, mediante o uso de PROC MIXED do SAS 8.2 (STATISTICAL ANALYSIS SYSTEM, 2001), com as médias comparadas pelo teste de Tukey a $5 \%$ de probabilidade.

\section{Resultado e Discussão}

Analisando os dados médios qualitativos da forragem pastejada (simulado) pelos animais (Tabela 1), verificou-se que a forragem apresentou bom valor nutritivo durante o período experimental em virtude das condições favoráveis de temperatura, luminosidade e precipitação, permitindo, assim, as mesmas condições de pastejo para os animais.

$\mathrm{O}$ teor de $\mathrm{PB}$ do pasto, em média, foi de $10,3 \%$, indicando que os animais possivelmente consumiram forragem com teores de $\mathrm{PB}$ superiores aos valores críticos de 6 a 8\%, o que limita a ingestão de MS devido à redução na fermentação ruminal e na digestão da forragem (REIS et al., 2009). Esses níveis de PB são considerados, por esses autores, como mínimos. Dessa forma, a suplementação contribuirá, de forma significativa, para melhor aproveitamento do pasto, principalmente em regiões tropicais, onde o pasto constitui a fonte principal da alimentação de bovinos, além de ser a de menor custo.

Os valores médios de MS, FDN, FDA, celulose, hemicelulose e lignina no pré-pastejo simulado foram de $23,7,67,4,32,7,28,6,33,8$ e $3,9 \%$, respectivamente (Tabela 1 ).

As forragens tropicais correspondem à fonte energética de menor custo para produção bovina nos trópicos (DETMANN et al., 2014) e apresentam elevado conteúdo de FDN, que chega, com frequência, a mais de $60 \%$ da MS total, como encontrado no presente estudo. As gramíneas tropicais possuem elevada porção de compostos nitrogenados insolúveis em detergente neutro, considerados de lenta e incompleta degradação, podendo faltar compostos nitrogenados aos microrganismos ruminais para maximizar a produção microbiana (PAULINO; DETMANN; VALADARES FILHO, 2008).

Não foram observadas diferenças $(\mathrm{P}<0,05)$ em relação às condições do pasto em função dos ciclos de pastejo, exceto nas proporções de colmo verde e seco (Tabela 2). Os valores médios de massa de forragem foram de 7,8 $\mathrm{t}$ de $\mathrm{MS} / \mathrm{ha}$, propiciando ofertas de massa de forragem de $15 \mathrm{~kg}$ de MS/100 kg de PC. Nesse sentido, Hodgson (1990) sugeriu como oferta máxima de consumo de MS de pasto o valor de 10 a $12 \mathrm{~kg}$ de $\mathrm{MS} / 100 \mathrm{~kg}$ de PC, estando esse valor inferior ao obtido no presente trabalho.

Com relação ao consumo de forragem, Paula et al. (2012) citam que a maior oferta de forragem aumenta a ingestão de MS, desde que essa maior oferta de forragem não ocorra com redução na relação folha: colmo (Tabela 2). Assim, a função do manejo do pastejo é adequar a frequência e intensidade de desfolhação para que o animal possa colher forragem com idade fisiológica adequada, evitando o acúmulo de tecidos lignificados que se correlacionam negativamente com os teores de PB e digestibilidade in vitro da MS (REIS et al., 2012).

A oferta média de folhas, em $\mathrm{kg}$ de MS $/ 100 \mathrm{~kg}$ de PC, foi de 3,7 (Tabela 2). Sabe-se que a massa de forragem pode limitar o consumo dos animais em pastejo, no entanto a quantidade de MS total foi sempre superior a $2 \mathrm{mil} \mathrm{kg} / \mathrm{ha}$ de MS total (Tabela 2). Flores et al. (2008) e Paula et al. (2010) confirmaram que a massa de forragem total inferior a $2 \mathrm{mil} \mathrm{kg} / \mathrm{ha}$ pode limitar o consumo voluntário 
dos animais em pastejo, e, com isso, obter-se-ia um desempenho abaixo do esperado.

Os ajustes na taxa de lotação foram realizados ao longo do período experimental (ciclos de pastejo), procurando-se manter a mesma oferta entre os tratamentos, fato esse conseguido com o manejo adotado (Tabela 2). A taxa média de lotação no final do período experimental foi de 2,8 UA/ha. Esse resultado foi inferior ao relatado por Flores et al. (2008), que encontraram taxa de lotação média de 3,4 UA/ha, na época das águas, em pasto de capim Marandu manejado com altura do dossel, na entrada, de $40 \mathrm{~cm}$.

$\mathrm{O}$ ganho de peso médio diário dos animais $(0,446,0,535,0,769$ e $0,848 \mathrm{~kg} / \mathrm{animal}$, respectivamente para os níveis de $0,0,3,0,6$ e $0,9 \%$ de suplemento/ $\mathrm{kg}$ de $\mathrm{PC}$ ) aumentou linearmente $(\mathrm{P}<0,001)$ com os níveis crescentes do suplemento (Tabela 3 ).

Tabela 2. Valores médios de altura de entrada $(\mathrm{cm})$, massa de forragem $(\mathrm{MF})$, em $\mathrm{t}$ de $\mathrm{MS} / \mathrm{ha}$, $\mathrm{t}$ de massa verde seca (MVS)/ha e t de folha verde (MFV)/ha, folha verde (FV), colmo verde (CV), folha senescente (FS), colmo senescente $(\mathrm{CS})$, em porcentagem na MS, relação folha: colmo total (F:C total), relação folha verde: colmo verde (FV:CV), oferta de forragem, expresso em $\mathrm{kg}$ de MS/100 kg de PC (OFMS), kg de MVS/100 kg de PC (OFMVS), kg de FV/100 kg de PC (OFFV) e taxa de lotação (TL) em função dos ciclos de pastejo.

\begin{tabular}{|c|c|c|c|c|c|c|c|}
\hline \multirow{2}{*}{ Variáveis } & \multicolumn{4}{|c|}{ Ciclos de pastejo ${ }^{1}$} & \multirow{2}{*}{ Médias } & \multirow{2}{*}{$C V^{2}$} & \multirow{2}{*}{$\operatorname{Pr}>\mathbf{F}^{3}$} \\
\hline & 1 & 2 & 3 & 4 & & & \\
\hline Altura & 37,78 & 31,59 & 34,57 & 38,60 & 35,71 & 32,24 & 0,82 \\
\hline MF & 8,1 & 7,8 & 8,6 & 6,5 & 7,8 & 18,17 & 0,25 \\
\hline MVS & 4,7 & 4,8 & 3,9 & 4,2 & 4,4 & 19,39 & 0,42 \\
\hline MFV & 2,1 & 2,2 & 1,6 & 1,9 & 1,9 & 28,37 & 0,38 \\
\hline FV & 25,8 & 28,7 & 19,5 & 28,6 & 25,6 & 26,47 & 0,23 \\
\hline $\mathrm{CV}$ & $32,6 a b$ & $33,1 \mathrm{ab}$ & $27,8 b$ & $34,17 \mathrm{a}$ & 31,9 & 8,50 & 0,03 \\
\hline FS & 20,2 & 18,7 & 22,5 & 19,9 & 20,3 & 15,65 & 0,44 \\
\hline $\mathrm{CS}$ & $21,4 \mathrm{ab}$ & $19,4 \mathrm{ab}$ & $30,3 \mathrm{a}$ & $17,3 b$ & 22,1 & 24,42 & 0,02 \\
\hline $\mathrm{F}: \mathrm{C}$ total & 0,88 & 0,91 & 0,75 & 0,95 & 0,87 & 26,25 & 0,66 \\
\hline $\mathrm{FV}: \mathrm{CV}$ & 0,80 & 0,87 & 0,71 & 0,84 & 0,80 & 31,02 & 0,81 \\
\hline OFMS & 16,7 & 15,7 & 15,6 & 12,2 & 15,0 & 21,23 & 0,26 \\
\hline OFMVS & 9,8 & 9,6 & 7,2 & 7,8 & 8,6 & 22,54 & 0,20 \\
\hline OFFV & 3,8 & 4,4 & 2,9 & 3,6 & 3,7 & 28,12 & 0,25 \\
\hline TL (UA/ha) & 2,6 & 2,7 & 2,9 & 2,9 & 2,8 & 8,99 & 0,28 \\
\hline
\end{tabular}

Médias seguidas da mesma letra na linha não diferem entre si pelo teste Tukey $(\mathrm{P}>0,05) .{ }^{1}$ Ciclos de pastejo $=1(19 / 01 / 2010$ a 24/02/2010); 2 (25/02/2010 a 01/04/2010); 3 (02/04/2010 a 07/05/2010); 4 (08/05/2010 a 12/06/2010); ${ }^{2} \mathrm{CV}=$ Coeficiente de variação; ${ }^{3}$ Valores de $p$.

Tabela 3. Peso corporal inicial (PCI) e final (PCF), ganho médio diário por animal (GMD), perímetro torácico inicial (PTI) e final (PTF), altura da cernelha inicial (ACI) e final (ACF), comprimento da garupa inicial (CGI) e final (CGF), condição corporal inicial (CCI) e final (CCF) em função dos níveis de suplementação.

\begin{tabular}{|c|c|c|c|c|c|c|c|}
\hline \multirow{2}{*}{ Variável } & \multicolumn{4}{|c|}{ Níveis de suplementação (\%PC) } & \multirow{2}{*}{ EPM } & \multicolumn{2}{|c|}{$P$ valor ${ }^{2}$} \\
\hline & $\mathbf{0}$ & 0,3 & 0,6 & 0,9 & & $\mathbf{L}$ & $\mathbf{Q}$ \\
\hline PCI & 237,6 & 243,7 & 252,1 & 240,6 & 26,00 & 0,731 & 0,435 \\
\hline $\mathrm{PCF}$ & 285,5 & 301,5 & 335,1 & 332,1 & 28,81 & $<0,01$ & 0,480 \\
\hline GMD & 0,446 & 0,535 & 0,769 & 0,848 & 0,055 & $<0,001$ & 0,895 \\
\hline PTI & 146,7 & 145,4 & 148,9 & 148,1 & 6,388 & 0,579 & 0,939 \\
\hline PTF & 153,2 & 155,1 & 160,6 & 158,4 & 6,237 & $<0,01$ & 0,465 \\
\hline $\mathrm{ACI}$ & 117,5 & 119,6 & 122,8 & 117,3 & 3,113 & 0,700 & $<0,01$ \\
\hline $\mathrm{ACF}$ & 123,2 & 125,3 & 129,9 & 124,2 & 3,138 & 0,362 & $<0,01$ \\
\hline CGI & 35,7 & 36,1 & 37,1 & 36,8 & 1,722 & 0,288 & 0,692 \\
\hline CGF & 41,1 & 41,6 & 43,2 & 42,2 & 1,363 & $<0,01$ & 0,222 \\
\hline $\mathrm{CCI}^{1}$ & 2,51 & 2,47 & 2,72 & 2,75 & 0,077 & $<0,001$ & 0,600 \\
\hline $\mathrm{CCF}^{1}$ & 2,82 & 2,72 & 2,85 & 2,95 & 0,077 & $<0,01$ & 0,122 \\
\hline
\end{tabular}

${ }^{1}=$ escore corporal inicial e final (escala de 1, muito magra, a 5, muito gorda); ${ }^{2}$ Valores de $p$. 
Ao comparar os animais suplementados e não suplementados, observa-se, de forma geral, desempenho superior dos animais suplementados. O uso de suplemento concentrado possibilitou um incremento no ganho de peso de $0,089,0,323$ e $0,402 \mathrm{~kg} / \mathrm{animal} /$ dia para as doses de $0,3,0,6$ e $0,9 \%$ de suplemento, respectivamente.

Segundo Porto et al. (2009), animais frequentemente respondem à suplementação durante a estação das águas, com ganhos adicionais de 200 a 300 g. Isso pode não ser significativo quando se compara apenas o ganho de peso com o custo do suplemento múltiplo, principalmente em épocas em que o custo do suplemento é alto, mas pode causar grande impacto no sistema de produção como um todo. A utilização de fêmeas mais jovens para reposição do rebanho, a desocupação de áreas para o diferimento das pastagens e o aumento da eficiência em converter alimento em produto animal possivelmente seriam uma das maiores vantagens da suplementação nas águas.

Fischer et al. (2005), suplementando bezerros sob pastejo contínuo com lotação variável, mantendo a oferta de MS entre 7 a $10 \mathrm{~kg}$ por $100 \mathrm{~kg}$ de peso vivo, em pastagem com média de $12,3 \%$ de $\mathrm{PB}$, observaram que animais recebendo níveis de suplemento à base de sorgo moído na ordem de 0,75 e $1,5 \%$ do PV, com composição química média de $8 \%$ PB e $45 \%$ de FDN, ganharam mais peso que os não suplementados. Entretanto, nos períodos de caracterizados pela boa qualidade e alta disponibilidade da pastagem, não houve diferença no ganho de peso diário entre os grupos que receberam níveis variados de suplemento.

Barbosa et al. (2008), trabalhando com suplemento proteico-energético para novilhos mestiços Holandês x Gir na época de transição água-seca, com 0,17 ou $0,37 \%$ do peso vivo ou apenas sal mineral, observaram diferenças no ganho médio diário entre os tratamentos. Os animais que receberam a quantia de suplemento correspondente a $0,17 \%$ do PV obtiveram ganhos superiores da ordem de $0,120 \mathrm{~kg} /$ novilho/dia e aqueles que receberam suplemento correspondente a $0,37 \%$ do PV obtiveram ganhos superiores da ordem de $0,211 \mathrm{~kg} /$ novilho/dia, em relação aos que receberam apenas sal mineral. Tais resultados evidenciam que, mesmo nessa época, a suplementação proteico-energética promove ganhos significativos.

Porto et al. (2011), trabalhando com quantidades de suplementos múltiplos para machos na recria, reportaram maior ganho de peso médio diário (GMD) para os animais suplementados em comparação ao tratamento controle (485 versus $257 \mathrm{~g} / \mathrm{dia}$, respectivamente) e também observaram resposta crescente do GMD à oferta de suplemento.

Houve efeito linear $(\mathrm{P}<0,01)$ no perímetro torácico final, no comprimento da garupa final, no escore da condição corporal inicial e final e efeito quadrático $(\mathrm{P}<0,01)$ na altura da cernelha inicial e final em função dos níveis crescentes de suplemento (Tabela 3).

Segundo Radcliff et al. (1997), apenas informações com relação ao PC não são suficientes para a descrição do animal, pois um animal pode ser baixo e gordo e pesar mais que um animal alto e magro. Dessa forma, a altura da cernelha, o comprimento de garupa e o perímetro torácico são mensurações utilizadas para estimar o tamanho do esqueleto, o que é de suma importância no parto, no intuito de evitar distocia ou desordens metabólicas pós-parto, pois novilhas menores e gordas são mais propensas a apresentar maior incidência desses problemas.

Além disso, a análise da condição corporal é um bom indicador do desenvolvimento muscular e da deposição de gordura subcutânea, os quais têm correlação com o desempenho reprodutivo e crescimento das novilhas (VAZ; LOBATO, 2010).

Desse modo, essas informações sobre peso e medidas corporais das novilhas em diferentes idades podem auxiliar técnicos e produtores no manejo dos animais mestiços, fornecendo expectativas de crescimento e, consequentemente, servindo como referência para práticas de manejo nas propriedades, em especial no estabelecimento do tamanho ideal para a inseminação.

\section{Conclusão}

O uso de suplemento proteico-energético no período das águas proporciona maior aporte de nutrientes e melhora o desempenho de novilhas mestiças criadas em pastagem de Brachiaria brizantha quando comparadas a animais suplementados somente com sal mineral.

\section{Referências}

ASSOCIATION OF ANALYTICAL CHEMISTS - AOAC. Official methods of analysis. 12th ed. Washington: AOAC, 1975. $1094 \mathrm{p}$. 
BARBOSA, F. A. et al. Análise econômica da suplementação proteico-energética de novilhos durante o período de transição entre água-seca. Arquivo Brasileiro de Medicina Veterinária e Zootecnia, v. 60, n. 4, p. 911-916, 2008.

CASAGRANDE, D. R. et al. Canopy characteristics and behavior of Nellore heifers in Brachiaria brizantha pastures under different grazing heights at a continuous stocking rate. Revista Brasileira de Zootecnia, v. 40, p. 2294-2301, 2011.

DETMANN, E. et al. An evaluation of the performance and efficiency if nitrogen utilization in cattle fed tropical grass pastures with supplementation. Livestock Science, v. 162, p. 141-153, 2014.

FISCHER, V. et al. Ganho de peso de novilhos mantidos em pastagem natural na encosta do sudeste do Rio Grande do Sul, recebendo níveis crescentes de suplementação energética. Revista Brasileira de Zootecnia, v. 34, p. 159-166, 2005.

FLORES, R. S. et al. Desempenho animal, produção de forragem e características estruturais dos capins marandu e xaraés submetidos a intensidades de pastejo. Revista Brasileira de Zootecnia, v. 37, n. 8, p. 1355-1365, 2008.

HODGSON, J. Grazing management: science into practice. New York: Longman Scientific \& Technical, 1990. 203 p.

JOHNSON, A. D. Sample preparation and chemical analysis of vegatation. In: T'MANEJET, L. (Ed.). Measurement of grassland vegetation and animal production. Aberustwysth: Commonwealth Agricultural Bureaux, 1978. p. 96-102.

MORETTI, M. H. et al.. Performance of Nellore young bulls on Marandu grass pasture with protein supplementation. Revista Brasileira de Zootecnia, v. 42, n. 6, p. 438-446, 2013.

NATIONAL RESEARCH COUNCIL - NRC. Nutriente requirements of dairy cattle. 7 th ed. Washington: National Academic Press, 2001.280 p.

OLIVEIRA, A. A. Manejo do pasto de capimmarandu e suplementação com diferentes fontes de energia na recria de tourinhos Nelore. 2014. Tese (Doutorado em Zootecnia) - Universidade Estadual Paulista "Júlio de Mesquita Filho",
Faculdade de Ciências Agrárias e Veterinárias de Jaboticabal, 2014.

PAULA, C. C. L. et al. Estrutura do dossel, consumo e desempenho animal em pastos de capim-marandu sob lotação contínua. Arquivo Brasileiro de Medicina Veterinária e Zootecnia, v. 64, n. 1, p. 169-176, 2012.

PAULA, N. F. et al. Frequência de suplementação e fontes de proteína para recria de bovinos em pastejo no período da seca: desempenho produtivo e econômico. Revista Brasileira de Zootecnia, v. 39, n. 4, p. 873-882, 2010.

PAULINO, M. F.;, S. C. Bovinocultura funcional nos trópicos. In: SIMPÓSIO DE PRODUÇÃO DE GADO DE CORTE; SIMPÓSIO INTERNACIONAL DE PRODUÇÃO DE GADO DE CORTE, 2. 2008, Viçosa. Anais... Viçosa: SIMCORTE, 2008. p. 275-305.

PERES, A. A. C. et al. Custo de produção na recria de novilhas mestiças Holandês x Zebu em pastagem de capim-elefante. Boletim de Indústria Animal, v. 65, n. 2, p. 99-108, 2008.

PORTO, M. O. et al. Fontes suplementares de proteína para novilhos mestiços em recria em pastagens de capim-brachiaria no período das águas: desempenho produtivo e econômico. Revista Brasileira de Zootecnia, v. 38, n. 8, p. 1553-1560, 2009.

PORTO, M. O. et al. Ofertas de suplementos múltiplos para tourinhos nelore na fase de recria em pastagens durante o período da seca: desempenho produtivo e características nutricionais. Revista Brasileira de Zootecnia, v. 40, n. 11, p. 25482557, 2011.

RADCLIFF, R. P. et al. Effects of diet and bovine somatotropin on heifer growth and mammary development. Journal of Dairy Science, v. 80, n. 9, p. 1996-2003, 1997.

REIS, R. A.; BARBERO, R. P.; KOSCHECK, J. F. W. Manejo de pastagens tropicais e suplementação alimentar para bovinos. In: CONGRESSO LATINOAMERICANO DE NUTRIÇÃO ANIMAL, 6 ., 2014, São Pedro, SP. Anais... São Pedro, 2014.

REIS, R. A. et al. Suplementação da dieta de bovinos de corte como estratégia do manejo de 
pastagem. Revista Brasileira de Zootecnia, v. 38, p. 147-159, 2009. Suplemento especial.

REIS, R. A. et al. Suplementação como estratégia de produção de carne de qualidade em pastagens tropicais. Revista Brasileira de Saúde e Produção Animal, v. 13, n. 3, p. 642-655, 2012.

ROBERTSON, J. B.; VAN SOEST, P. J. The detergent system at analysis and its application to human foods Integrated feeding systems. In: JAMES, W. P. T.; THEANDER, O. (Ed.). The analysis of dietary fiber in food. New York: Marcel Dekker, 1981. p. 123-158.

SOLLENBERGER, L. E.; CHERNEY, D. J. R. Evaluating forage production and quality: the science of grassland agriculture. Iowa: State University Press, 1995. p. 97-10.

STATISTICAL ANALYSIS SYSTEM - SAS. User's guide: statistics, version 8.2. Cary: SAS Institute, 2001.
VALENTE, A. L. S. Effect of pasture management and strategic supplementation on beef cattle production. Tese (Doutorado em Produção Animal) - Universidade Estadual Paulista "Júlio de Mesquita Filho", Faculdade de Ciências Agrárias e Veterinárias de Jaboticabal, 2015.

VAZ, R. Z.; LOBATO, J. F. P. Efeito da idade do desmame no desenvolvimento de novilhas de corte até os 14/15 meses de idade. Revista Brasileira de Zootecnia, v. 39, n. 2, p. 289-298, 2010.

VILLELA, S. D. J. et al. Suplementação para bovinos em pastejo no período de transição águasseca: variáveis nutricionais. Revista Brasileira de Saúde e Produção Animal, v. 11, n. 4, p. 10331045, 2010.

WILDMAN, E. E. et al. A dairy cow body condition scoring system and its relationship to selected production characteristics. Journal of Dairy Science, v. 65, p. 495-501, 1982. 